\title{
IMPLEMENTASI SISTEM INFORMASI PELANGGAN PT. TELKOM KANDATEL UNGARAN
}

\author{
Moch. Subchan Mauludin*, Mustagfirin dan Misbahudin \\ Program Studi Teknik Informatika Fakultas Teknik Universitas Wahid Hasyim \\ Jl.Menoreh Tengah X/22 Sampngan Semarang 50236 \\ *Email: aan.subhan18@gmail.com
}

\begin{abstract}
Abstrak
Implementasi system informasi pelanggan PT. Telkom merupakan kelanjutan dari peernacnagan yang sudah terlebih dahulu dilakukan. Implememtasi system informasi ini terbukti lebih praktis dalam pencarian data pelanggan PT. Telkom Kandatel Ungaran. Algoritma KMP (Knut Morris Pratt) dan SDLC merupakan metode yang digunakan dalam system ini. Algoritma KMP bekerja dengan mencocokan dengan tepat string yang ada di dalam urutan karakter yang ada di string. Implementasi Sisitem informasi pelanggan ini sangat relevan di gunakan di PT. Kandatel Ungaran.
\end{abstract}

Kata kunci : KMP, pelanggan, system development, sistem informasi

\section{PENDAHULUAN}

Standard dalam pelayanan diperlukan untuk menghasilkan pelayanan yang baik, standard pelayanan dapat dijadikan acuan dalam pengukuran pelayanan yang baik. Standard pelayanan bisa diukur secara kualitatif yaitu dengan mengukur waktu dan jumlah pelanggan yang terlayani. Standara yang lain yang dapat dijadikan acuan untuk pelayanan adalah opini yang didapatkan langsung dari konsumen.

Kecepatan waktu mulai dari pengakuan konsumen yang dating, menyapa serta berkomunikasi dengan elegan merupakan cara yang baik dalam melayani konsumen. Untuk membantu konsumen agar cepat dalam menangani permintaan pelanggan system informasi juga mutlak di perlukan.

Implementasi system informasi konsumen salah satu cara mempercepat pelayanan kepada konsumen. Sisitem informasi ini menjadi bagian yang sangan penting dalam menyelesaikan permintaan pelanggan. Implementasi system informasi pelanggan PT Telkom kandatel Ungaran mempercepat pelayanan kepada pelanggannya.

Sistem informasi yang merupakan kegiatan penginputan, pemrosesan, penyimpanan, pengontrolan, serta keluaran (Ladjumudin, 2005) untuk tujuan peningkatan dalam pelayanan.

\section{METODE}

\section{Metode $S D L C$}

Merupakan framework yang berisikan proses sekuensial system informasi yang akan di kembangkan (Turban, 2003). System
Development Life Cycle (SDLC) banyak digunakan pada pengembangan system saat ini. Urutan yang dilakukan pada SDLC disini adalah: Planning, analisa system, desain, implementasi, dan perawatan (Mauludin, 2017)

\section{Metode Pengembangan Perangkat Lunak} Perancangan dan penyelesaian masalah berpegang pada metode waterfall untuk mempermudah proses analisis dan perancangan (Kristanto, 2003). Urutan pengembangan perangkat lunak metode waterfall dapat dilihat pada Gambar 1. berikut ini:

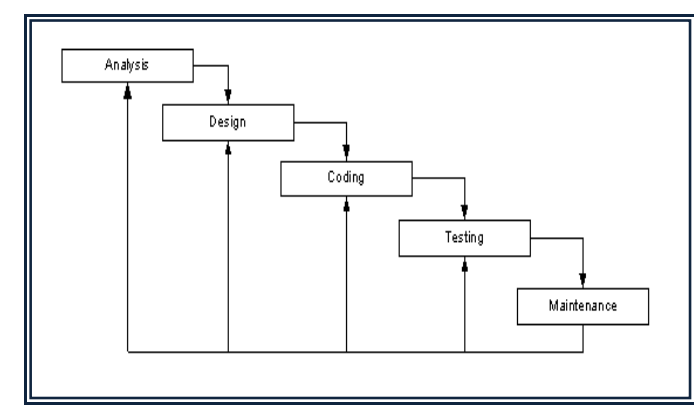

Gambar 1. Wterfall Method

\section{Algoritma Knut Morris Pratt}

Algoritma KMP merupakan pengembangan dari algoritma pencarian string sebelumnya, yaitu Algoritma Brute Force. Algoritma KMP merupakan algoritma yang digunakan untuk melakukan proses pencocokan string. Algoritma ini merupakan jenis Exact String Matching Algorithm yang merupakan pencocokan string secara tepat dengan susunan karakter dalam string yang sama.(Sa'diah, 2017)

\section{HASIL DAN PEMBAHASAN}




\section{Desain Sistem}

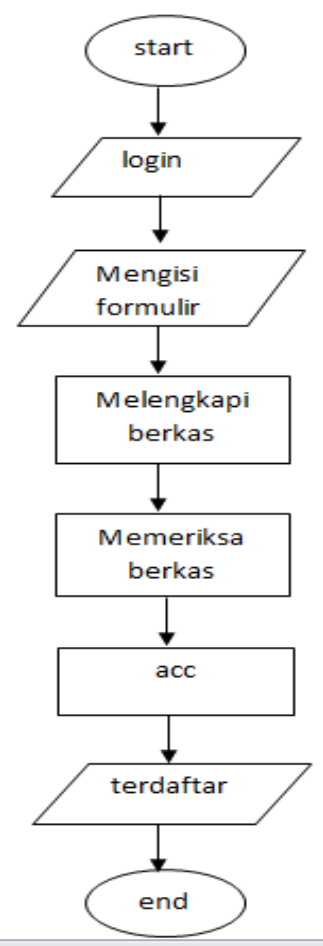

\section{Gambar 2 Flowchart sistem pendaftaran}

Flowchart pada Gambar 2, merupakan rancangan proses pendaftaran konsumen PT. Telkom Kandatel Ungaran, diawali dengan admin login untuk masuk kedalam system kemudian mengisikan data calon pelanggan sampai dengan akhir proses pendaftaran yaitu disetujui menjadi pelanggan.

\section{Diagram Kasus}

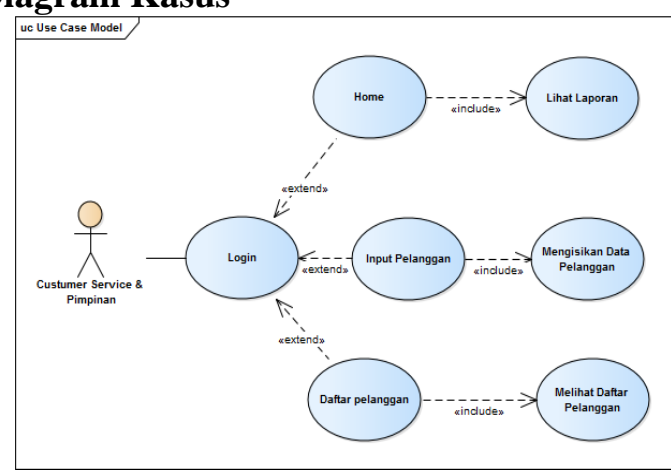

\section{Gambar 3. Diagram Kasus}

Gambar 3. Menjelaskan hubungan atau interaksi antar actor yang ada di system informasi. Diagram kasus bahwa CS serta pimpinan dapat menginput atau melihat laporan setelah melakukan login terlebih dahulu.

\section{Diagram Aktifitas}

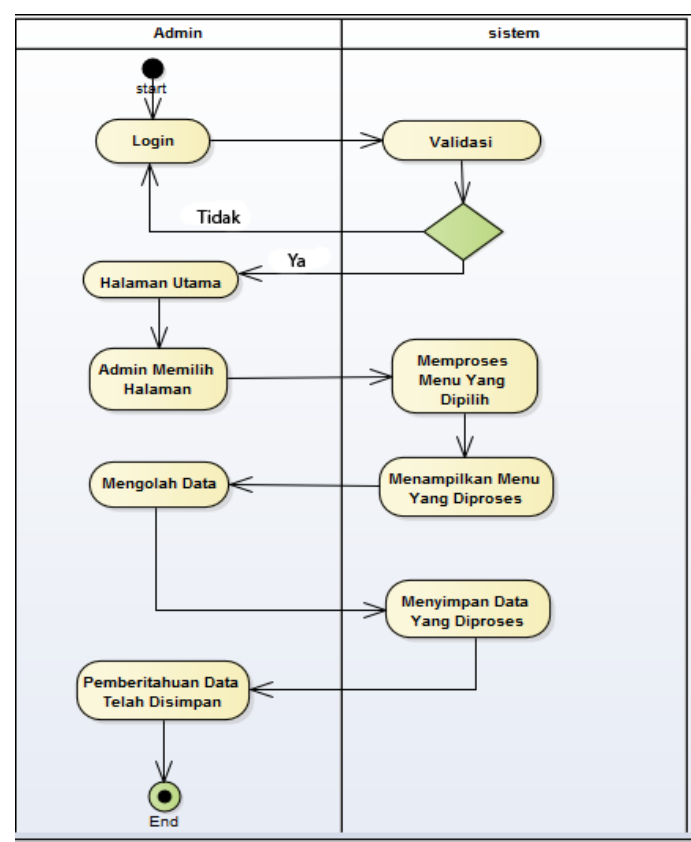

Gambar 4. Diagram Aktifitas

Diagram aktifitas pada gambar 4. merupakan pemodelan dari jalan kerja dalam sebuah proses system informasi, digambarkan setelah admin memasukan password dan user dengan benar system akan menjalankan proses selanjutnya sesuai yang dipilih.

\section{Database}

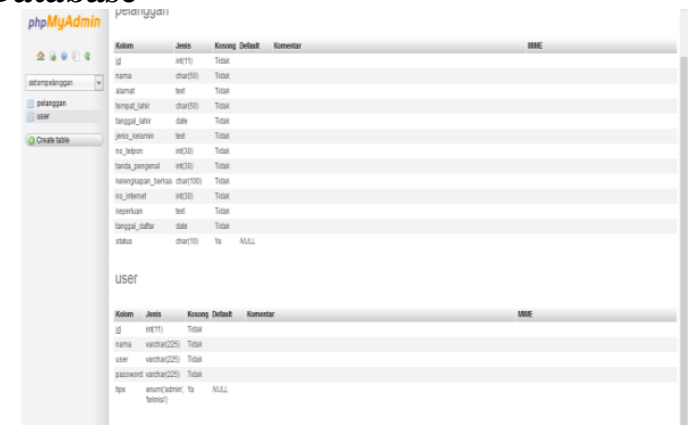

\section{Gambar 5. Tampilan Database}

Gambar 5 diatas adalah tampilan struktur database dalam sistem ini, dalam struktur database ini terdiri dari nama kolom dan type jenisnya. Database ini akan menampung semua inputan dari sistem ini.

Halaman Masuk Sistem 


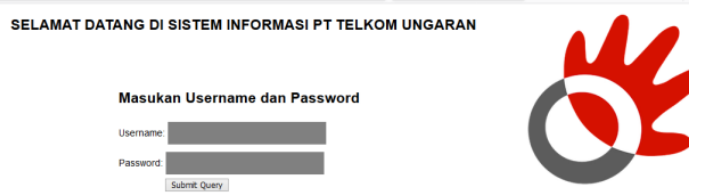

\section{Gambar 6. Halaman Masuk}

Admin atau costumer service sebelum memasukan data calon konsumen harus masuk melalui halam ini dan memasukan user dan password yang telah di buat. User dan password bersifat rahasia untuk menjamin keamanan system yang telah di buat.

\section{Halaman Awal}

Setelah admin berhasil masuk akan di tampilkan halaman awal dari system, halam utama menampilkan grafik pelanggan yang sudah terdaftar baru maupun pelanggan yang migrasi, grafik disajikan dalam perbulan. Gambar 7 merupakan tampilan halaman awal pada system yang dibuat.

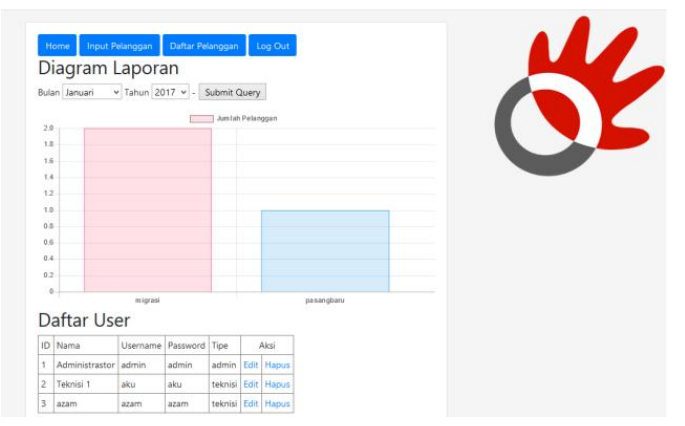

Gambar 7. Halam Awal

\section{Form Pendaftaran}

Form pendaftaran konsumen berisikan data calon pelanggan yang diisikan oleh admin atau customer service. Setelah data terinputkan di formn pendaftaran data otomatis akan tersimpan di data base system. Gambar 8 merupakan formulir yang harus diisikan oleh admin untuk menginputkan data calon pelanggan.

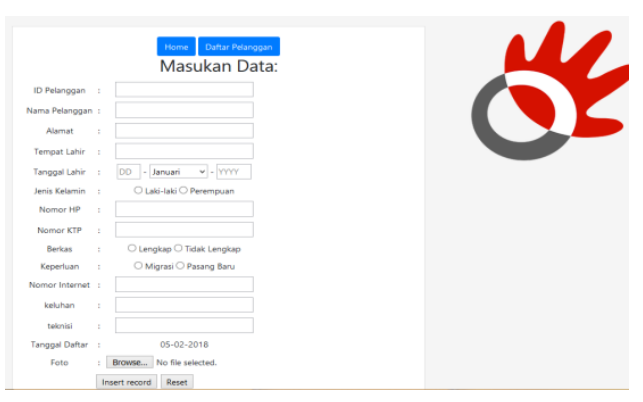

Gambar 8. Form Pendaftaran

\section{Daftar Pelanggan}

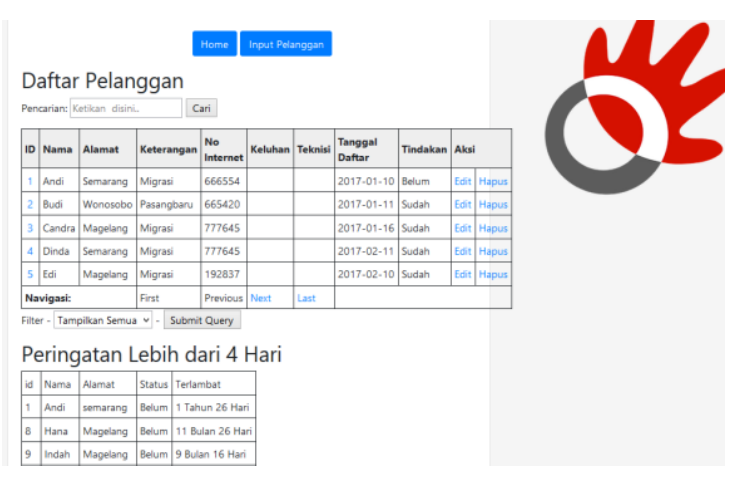

\section{Gambar 9. Daftar Pelanggan}

Daftar pelanggan di tampilkan sesuai dengan inputan yang diisiakan pada form pendaftaran. Pada halaman ini daftar pelangan hanya di tampilkan per nama pelanggan sepewrti terlihat pada gambar 9, secara detaial dapat di tampilkan lewat data detail pelanggan seperti terlihat pada gambar 10.

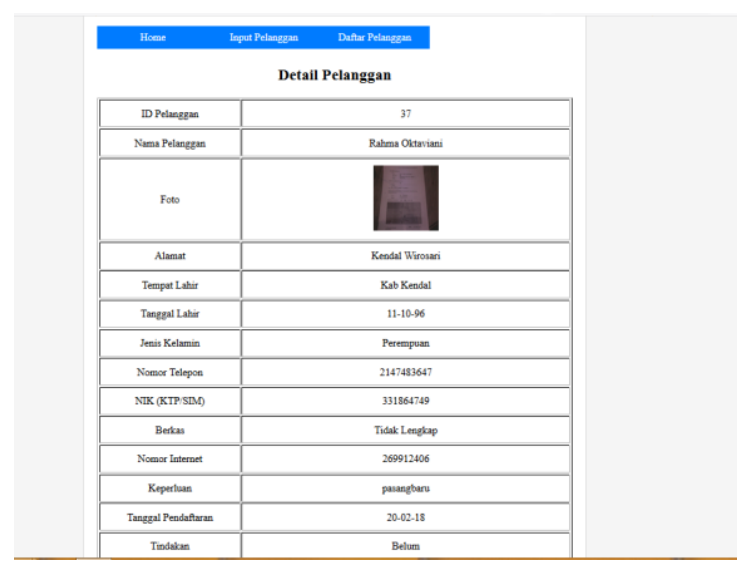

Gambar 10. Daftar Detail Pelanggan

\section{Pengujian}

Pada Tabel 1 memperlihatkan metode pengujian black box yang menunjukan keberhasilan dalam pembuatan sistem. 
Tabel 1. Pengujian Balck Box

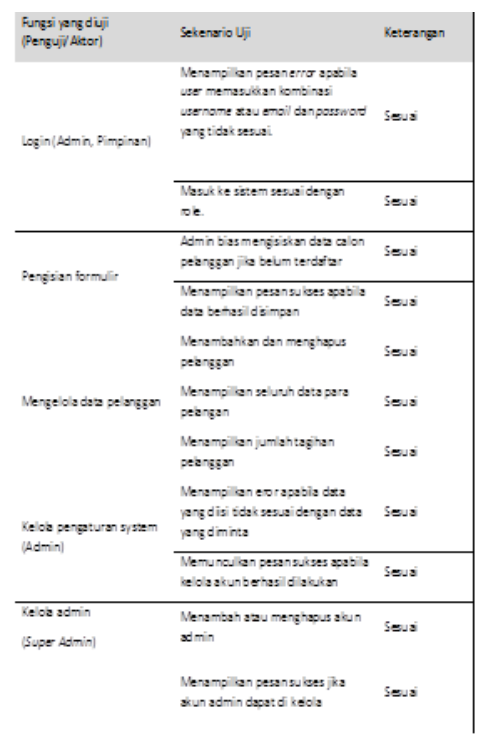

\section{KESIMPULAN}

Sistem informasi dapat digunakan sebagai sistem informasi data pelanggan pada PT. Telkom Kandatel Ungaran, sistem informasi ini telah meliputi tahap pengujian dengan menggunakan metode Black Box hasil pengujian dari sistem informasi ini menunjukan bahwa setiap proses pada sistem ini berjalan dengan baik dan sesuai dengan rancangan.

Sistem informasi ini menerapkan algoritma knuth morris pratt pada sistem ini proses pencarian data menjadi lebih cepat, akurat dan relevan.

\section{DAFTAR PUSTAKA}

Halimah Tus Sa'diah. 2017. Jurnal "implementasi algoritma knuth morris pratt pada fungsi pencarian judul tugas akhir repository". Jurnal komputasi, vol 14.

Kristanto A. 2003. Perancangan Sistem Informasi dan Plikasinya. Yogyakarta: Gava Media.

Ladjamudin AB. 2005. Analisis dan Desain Sistem Informasi. Graha Ilmu: Yogyakarta.

Mauludin. M. S, 2017, Peracangan dan Desain Sistem Customer PT. Telekomunikasi Indonesia (Telkom) Kandatel Ungaran, Fakultas Teknik Universitas Muria Kudus, Jurnal SIMETRIS, Vol 8 No 1 April 2017,ISSN 2252 - 4983

Turban E. 2004. Information to Information Tecnology, John Wiley \& Sons, USA. 